\title{
Teaching and Practice Mode Reform in Digital Image Processing Curriculum
}

\author{
Zhonghua Wang and Jun Guo
}

\begin{abstract}
The traditional teaching mode of the digital image processing, which is centered on teachers, textbooks and classrooms, hinders the requirements of the image technology development and impedes the cultivation of the innovative talents. Though the digital image processing is one of the emerging technology, it has been rapidly developed and widely used in the electronic information technology. In order to adapt to its development, this paper has explored the teaching and practice reform on the digital image processing curriculum, including the teaching objective, content setting, experiment platform and innovative training. Compared with the traditional teaching mode, it is shown that the teaching and practice reform of the course can not only strengthen the undergraduates' theoretical basises, but also improve their practical and innovative abilities.
\end{abstract}

Index Terms-Undergraduate, digital image processing, electronic information, teaching and practice reform.

\section{INTRODUCTION}

The digital image processing is one of important specialized courses in the electronic information discipline, which contains multiple-domain knowledge of mathematics, physics, electronics, communications, computer science, and so on [1], [2].

With rapid development of electronic information technology, the digital image processing technology is widely applied from a variety of weapon equipments of national defense construction to advanced medical imaging equipments, from numerous consumer electronic products and 3G multimedia communications [3], [4]. Therefore, learning this course, the electronic information undergraduates can not only master the basic concept, principle and algorithm of image processing, but also innovate on the fundamental framework of application technology. However, because of the characteristics of high starting point, great difficulty, strongly theoretical and practical combination of digital image processing course, its teaching objective, content setting, experimental platform and innovative teaching and practice mode must be provided by higher requirements and standards. So, the teacher should not only pay attention to the teaching of basic theoretics of the course, but also strengthen the undergraduates' engineering and practice abilities [5], [6]. Therefore, this paper intends to discuss and construct the teaching practice mode of the course system of digital image processing.

Manuscript received April 12, 2016; revised July 1, 2016.

The authors are with Nanchang Hangkong University, China (e-mail: wangzhonghua@nchu.edu.cn).
The remainder of this paper is organized as follows: in Section II, we analyze the domestic and foreign related research on the teaching and practice mode of digital image processing curriculum. The suggestions on establishing the curriculum system of image processing are described in Section III, and the Section IV gives a summary of the curriculum teaching and practice reform.

\section{ANALYSIS OF THE DOMESTIC AND FOREIGN RELATED RESEARCH ON DigITAL IMAGE PROCESSING TEACHING}

It is well known that the success of teaching practice reform depends to a large extent on improving the learning enthusiasm and initiative of undergraduates, cultivating the high-quality and top-notch innovative talents of abundant knowledge and excellent skill [7], [8]. In recent years, the research universities in the United States and Europe have made great experience from the course teaching reform, which is of great significance to the undergraduate's comprehensive quality [9], [10].

Though the existing curriculum system of electronic information has been set up relatively perfectly and the practice of specialized course have been established comparatively comprehensively, the current curriculum framework is payed attention to the knowledge teaching and ignored the undergraduate's ability training of introducing, analyzing, solving and evaluating question. Therefore, it is lack of the ability training that the students' technology innovation abilities are restricted. Then, the reform of teaching practice mode of digital image processing curriculum is not only feasible, but also very necessary [11], [12].

In vast majority of universities or colleges in China, the electronic information discipline emphasizes the hardware circuit design and software development as the core, as well as the engineering application as the goal. Adopting the programming language of Visual c++ or Matlab, the existing various experiments of digital image processing depend on the computer platform to realize the image processing simulations [13], which neglect the undergraduate's design ability of the integrated electronic system, as well hinder the cognition ability of the engineering project [14], [15].

To design the content framework system of digital image processing as the core, to improve the undergraduates' practice and innovation abilities as the purpose, to reform the teaching-practice mode of the course as the method, we should carry out a series of the reform on the teaching objective, content setting, experiment platform and innovative training in digital image processing curriculum in electronic information technology. 


\section{Suggestions On TEACHING -PRACTICE REFORM OF IMAGE PROCESSING CURRICULUM SYSTEM}

In view of the characteristics of wide knowledge, high complexity and strong comprehensiveness of digital image processing, in order to build a scientific and reasonable digital image processing course system and improve the teaching effect in electronic information technology, the following suggestions are put forward: firstly, strengthening the mutual connection of all related curricula; secondly, updating the teaching contents and tracking the frontier research trends; thirdly, improving the teacher's scientific research ability and enriching the teaching method; finally, constructing the comprehensive experiment platform and improving the students' innovative practice ability.

\section{A. Improving the Mutual Connection of Digital Image Processing and Other Information Courses}

In all universities or colleges, there are information category curricula such as the signal and system, information theory, digital signal processing, random signal processing and digital image processing, and so on. The image processing involves three important properties: continuity, matrix, stochasticity. So, the mentioned former four information courses are the necessary theoretical basis of image processing, the latter digital image processing as a professional course is opened in high grade stage.

Digital image processing course requires students to own all kinds of mathematical basis such as vector, matrix, probability statistics, linear systems and have a certain programming skills.

Because of the more and miscellaneous knowledge of the course, the traditional teaching neglects the mutual relationship between other related curricula, the students can not establish a complete understanding of the teaching system. Therefore, in order to guide the students to learn the digital image processing course, we must reasonably arrange the connection relation of other curricula, which is shown by Fig. 1 .

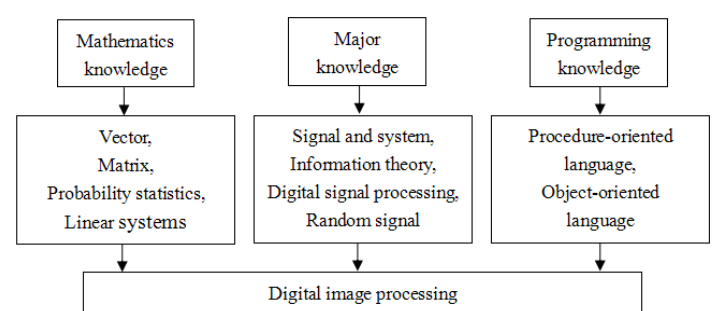

Fig. 1. The connection flowchart of digital image processing curriculum.

As shown in the Fig. 1, it is important that if the undergraduates own the good mathematics, major and programming knowledge, the students easily master the contents of digital image processing, which lay a basis for the further practice and innovation.

\section{B. Tracking the Frontier Research and Updating the Teaching Content}

Driven by emerging disciplines such as artificial intelligence, pattern recognition and machine learning, the updating speed of the teaching contents in digital image processing course has been far from the development of electronic information technology. Therefore, the course teaching contents should be adjusted to adapting to the progress of the times and further improved by appropriately introducing the frontier knowledge of disciplinary development and absorbing the related domestic and foreign research achievements.

In order to track the frontier research in image processing field, we should retrieval the authoritative journals or land the authoritative websites. So, the latest research findings ought to be appropriately chosen and supplemented as the teaching contents to keep up with the development of image processing technology.

In addition, we can form a experienced teaching and research team to edit the engineering textbooks of image processing from design to implementation. Then, the textbooks are used for conducting and improving the engineering practice abilities of the undergraduates.

Therefore, the frontier achievements and engineering textbooks of digital image process should be regularly introduced to the course teaching. The updating the curriculum content flowchart of image processing can be illustrated in Fig. 2.

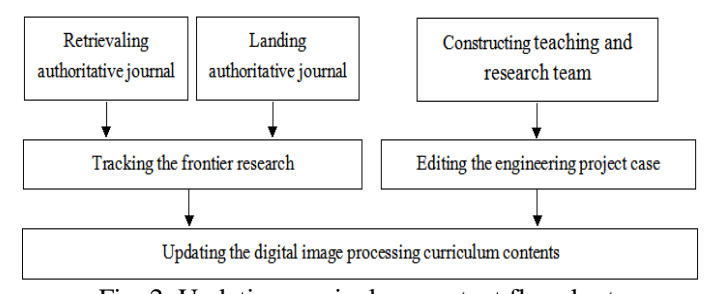

Fig. 2. Updating curriculum content flowchart.

\section{Improving the Teacher's Scientific Research Ability and Enriching the Teaching Means}

It is known that the scientific research and teaching is the relationship of mutual promotion. The improvement of teachers' scientific research ability is beneficial to the teaching content updating. Through the scientific research, the teachers will be exposed to more new knowledge. Through the cooperative development between university and enterprise, the applied technical talents can be more easily cultivated. So, let the students understand the scientific research essence and master the basic scientific research methods, which can effectively stimulate students' abilities of the independent and creative thinking.

At the same time, we can adopt a variety of teaching method in the digital image processing curriculum. Firstly, the multimedia teaching method has richly expressive force, which has vivid and visual features, so that the abstract concept can be concrete. Secondly, the examples of image processing in teaching will be demonstrated with Visual c++ or Matlab programming language. Thirdly, in the course of teaching, we should pay attention to the teaching methods, such as heuristic teaching, discussion teaching, to achieve the best teaching effect.

Whether heuristic teaching or discussion teaching in the image processing course, there includes three stages. First, the teacher choose a theme on content points to discuss in lecture. Then, the students are urged to think divergently. Finally, the feasibility and innovativeness of the discussed conclusion is 
commented by the teacher.

In summary, the teaching effect on image processing depends to a large extent on the scientific research ability and teaching means of teachers, whose mutual relation can be seen in Fig. 3. So, the students learn more practical knowledge so as to achieve a virtuous cycle of consensus, sharing and progress in teaching and learning mode.

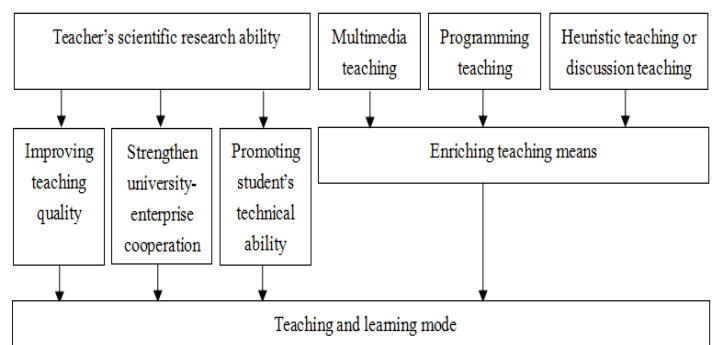

Fig. 3. The consensus, sharing and progress in teaching and learning mode.

\section{Constructing the Comprehensive Experiment Platform} and Improving the Students' Innovative Practice Ability

The image processing system in the hardware structure is adopted by the chip of TMS320DM642 of TI as the arithmetic platform, selected the chip of XC95144 of Xilinx as the core of controller that is used to assign into the time sequence in image collection, used SAA7111 to process the video signal and expanded SDRAM memory to storage the image. So, the system, which integrates the function of sensor, image sampling, real-time data and processing, is a image processing system of high performance.

Taking the enterprise project as the main line, establishing the real task, the knowledge and skill points in image processing will be decomposed into the concrete task, whose workflow can be seen in Fig. 4. It is proved that the powerful experiment platform plays a vital role for deepening the understanding of image processing theory and cultivating the undergraduates' practice abilities. Therefore, the following suggestions on how to improve the undergraduates' innovative practice abilities are put forward:

\begin{tabular}{|c|}
\hline Analyzing project \\
\hline Clarifying task \\
\hline \\
\hline Independent exploration \\
\hline \\
\hline Completing project \\
\hline \\
\hline
\end{tabular}

Fig. 4. The project implementation process

1) Constructing the software and hardware design platform based on DSP

Considered the development application of digital signal processor, the TI's video processing TMS320DM642 is chosen as the core to build the hardware platform in image processing system.

The based-DSP image processing experiment platform consists of the image acquisition module, minimum system module, control module, communication interface module, memory module and man-machine interface module, which incorporate the computer technology, image processing technology, control technology, electronic technology and other field knowledge, to realize the image input, image processing and image display function.

Therefore, adopting the DSP as the core, the experiment platform can effectively fulfills the collaborative development of hardware and software of the system. Designing TMS320DM6437 DSP-based core board, the undergraduates will learn the DSP functional interface and relevant technique, train the design of the $\mathrm{PCB}$ core board using PCB Editor, verify the signal integrity of the core board circuit, and further develop the system software and hardware design of the master machine and slavery machine. Meanwhile, the teachers can depend on the DSP experiment platform of visualization teaching to guide the undergraduates' studying on the image processing and analysis.

2) Reforming the practice teaching system and strengthening the practice level

The projects to realize the video image processing and digital communication has been proposed, focused on the design of video encoder by software and the peripheral hardware system using TMS320DM642. The precise acquisition of the video signals is fulfilled through the SAA7111 video acquisition chip and the XC95144 is applied in the design of the complex and high-speed logic control. Meanwhile, the RS232 serial port of TMS320DM642 is developed for wireless transmission. The wireless transmitting and receiving module NRF401, which has the RS232 serial port, is utilized to fulfill the software and hardware design of image data transmitting.

To positively carry out the basics, comprehensiveness and innovativeness practice of image processing, the undergraduates should be urged to participate in the engineering project development of the distortion correction, static or dynamic display, face recognition, license plate recognition, watermarking technology and other applications of digital image. Therefore, the structure, design, simulation, trans- plantation and optimization of the image processing algorithm is implemented and verified via the TMS320DM642 DSP-based hardware platform system.

In order to fully indicate the features of theory, analysis and application of the image processing, the experiment designs from easy to difficult, from simple to complex, from passive acceptance to active verification should gradually reflect the undergraduates' engineering practice abilities.

\section{CONCLUSION}

The characteristics of digital image processing course are analyzed in this paper, which reflects the perfect combination of the theory and experiment teaching, the practice and innovation training. Therefore, the digital image curriculum should not only owns the basic knowledge modules, but also embodies professional skill modules. To design the course system as the core, innovate the teaching-practice mode as the object, and improve the undergraduates' practice abilities as the purpose, this paper has explored the teaching and practice reform on the digital image processing curriculum, including the teaching objective, content setting, experiment platform 
and innovative training. The mentioned suggestions will improve the course teaching quality, enhance the undergraduates' engineering practice abilities and cultivate the high-quality innovative talents.

\section{ACKNOWLEDGMENT}

The authors gratefully thank the reviewers for their useful comments that lead to quality improvements of the paper and this work is supported by the Educational Science Planning Project of Jiangxi Province of China under Grant No. 16YB086, the Postgraduate Education and Teaching Reform of Jiangxi Province of China under Grant No. JXYJG2012071 and JXYJG2014126.

\section{REFERENCES}

[1] E. G. Ramirez and I. A. Garcia, "Using the project-based learning approach for incorporating an FPGA-based integrated hardware-software tool for implementing and evaluating image processing algorithms into graduate level courses," Computer Applications in Engineering Education, vol. 21, pp. 73-78, August 2013.

[2] Z. Tao, M. Heng, and L, Qiang, "Researches on case teaching in professional education," Journal of Higher Education Research, vol. 3 , pp. 91-93, July 2010

[3] J. Campbell, F. Murtagh, and M. Kokuer, "DataLab-J: A signal and image processing laboratory for teaching and research." IEEE Transactions on Education, vol. 4, pp. 329-335, December 2001.

[4] S.-T. Liu, J. Zhang et al., "The reform and innovation of research-oriented teaching mode of electronics and information courses," Journal of higher education research, vol. 34, no. 4, pp. 77-80, May 2011.

[5] P. Sharma, "DSP in image processing," International Journal of Advanced Research in Computer and Communication Engineering, vol. 4 no. 1, pp. 46-49, March 2015.

[6] G.-F. Wei et al., "Explore on teaching reform of digital image processing course," Journal of electrical \& electronic education, vol. 31 no. 6, pp. 24-25, August 2009.

[7] E. J. Leavline, D. A. A. G. Singh, and C. Zhang. "On teaching digital image processing with matlab," American Journal of Signal Processing, vol. 4, no. 1, pp. 7-15, May 2014.

[8] Y.-G. Wang et al., "Practical teaching reform for digital image processing based on project- driven," Emerging Computation and Information Technologies for Education Advances in Intelligent and Soft Computing, vol. 146, pp. 9-14, March 2012.

[9] S. P. D. Gedera, "Students' experiences of learning in a virtual classroom," International Journal of Education and Development Using Information and Communication Technology, vol. 10, no. 4, pp. 93-101, April 2014.

[10] X.-H. Hu et al., "Based on the working process of the image processing teaching reform exploration and practice," Computer Knowledge and Technology, vol. 9, no. 2, pp. 2891-2894, March 2013.

[11] C. Yan et al., "Teaching system of toilet spray glaze based on digital image processing," International Journal of Digital Content Technology \& Its Application, vol. 7, no. 9, p. 215, August 2013.

[12] A. G. D. Asir and L. E. Jebamalar, "Competency -based calisthenics of learning outcomes for engineering education," International Journal of Education and Learning, vol. 2, no. 1, pp.25-34, May 2013.

[13] E. J. Leavline and D. A. A. G. Singh, "On teaching digital image processing with matlab," American journal of signal processing, vol. 4, no. 1, pp. 7-15, August 2013.

[14] A. Trost and A. Emva, "Teaching design of video processing circuits," International Journal of Electrical Engineering Education, vol. 49, no. 2, pp. 170-178, March 2013.

[15] D. Sarma and K. K. Sarma, "Multicore parallel computing and DSP processor for the design of bio-inspired soft computing framework for speech and image processing application," Signals and Communication Technology, vol. 137, pp. 125- 134, March 2015.
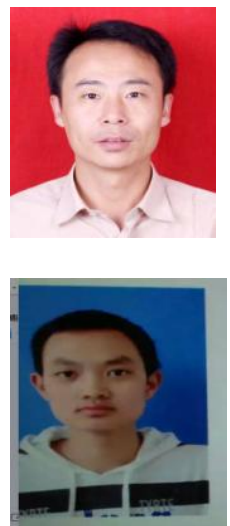

Zhonghua Wang was born in Jiangxi province, China He received the Ph.D. degree in control science and engineering. He is currently an associate professor of Nanchang Hangkong University, China. His research interests include teaching reform, practice training and artificial intelligence. He has hosted or attended several National Natural Science Fund Projects of China.

Jun Guo was born in Hunan province, China. He is currently a graduate student in the field of electronics and communication engineering. His research interests include pattern recognition and artificial intelligence. $\mathrm{He}$ has attended a National Natural Science Fund Project of China. 